\title{
Biomechanical characteristics of fixation methods for floating pubic symphysis
}

\author{
Wenhao Song, Dongsheng Zhou ${ }^{*}$ and Yu He
}

\begin{abstract}
Background: Floating pubic symphysis (FPS) is a relatively rare injury caused by high-energy mechanisms. There are several fixation methods used to treat FPS, including external fixation, subcutaneous fixation, internal fixation, and percutaneous cannulated screw fixation. To choose the appropriate fixation, it is necessary to study the biomechanical performance of these different methods. The goal of this study was to compare the biomechanical characteristics of six methods by finite element analysis.

Methods: A three-dimensional finite element model of FPS was simulated. Six methods were used in the FPS model, including external fixation (Ext), subcutaneous rod fixation (Sub-rod), subcutaneous plate fixation (Sub-plate), superior pectineal plate fixation (Int-sup), infrapectineal plate fixation (Int-ifa), and cannulated screw fixation (Int-scr). Compressive and rotational loads were then applied in all models. Biomechanical characteristics that were recorded and analyzed included construct stiffness, micromotion of the fracture gaps, von Mises stress, and stress distribution.

Results: The construct stiffness of the anterior pelvic ring was decreased dramatically when FPS occurred. Compressive stiffness was restored by the three internal fixation and Sub-rod methods. Unfortunately, rotational stiffness was not restored satisfactorily by the six methods. For micromotion of the fracture gaps, the displacement was reduced significantly by the Int-sup and Int-ifa methods under compression. The internal fixation methods and Sub-plate method performed well under rotation. The maximum von Mises stress of the implants was not large. For the platescrew system, the maximum von Mises stress occurred over the region of the fracture and plate-screw joints. The maximum von Mises stress appeared on the rod-screw and screw-bone interfaces for the rod-screw system.

Conclusions: The present study showed the biomechanical advantages of internal fixation methods for FPS from a finite element view. Superior stabilization of the anterior pelvic ring and fracture gaps was obtained by internal fixation. Subcutaneous fixation had satisfactory outcomes as well. Sub-rod fixation offered good anti-compression, while the Sub-plate fixation provided favorable anti-rotational capacity.
\end{abstract}

Keywords: Floating pubic symphysis, Biomechanical characteristics, External fixation, Subcutaneous fixation, Internal fixation

\section{Background}

Floating injuries have been discussed frequently in the literature and describe a unique fracture pattern; examples include floating shoulder [1], floating hip [2], and floating knee [3]. A floating joint is one that has lost its continuity at adjacent ends and has no bony attachments on either end [4]. The pubic symphysis is an oligodynamic joint and consists of bilateral pubic bones and a fibrocartilaginous disc. Fractures of the bilateral superior

\footnotetext{
*Correspondence: 408992708@qq.com; heyuworkmail@sina.com Department of Orthopedic Surgery, Shandong Provincial Hospital Affiliated to Shandong University, 324 Jingwu Road, Ji'nan, Shandong, People's Republic of China
}

and inferior pubic rami and ischial rami are considered to create a floating pubic symphysis (FPS). In this situation, the pubic symphysis has lost its continuity with the innominate bones and the anterior pelvic ring has become extremely unstable.

FPS is a relatively rare injury caused by high-energy mechanisms $[3,4]$ and causes a disruption in the normal biomechanical function of the anterior pelvic ring. Because the risk of hemorrhagic shock and rectal, urogenital, and vaginal injuries increases dramatically [5], the mechanical and architectural stability of the anterior pelvic ring must be restored. 


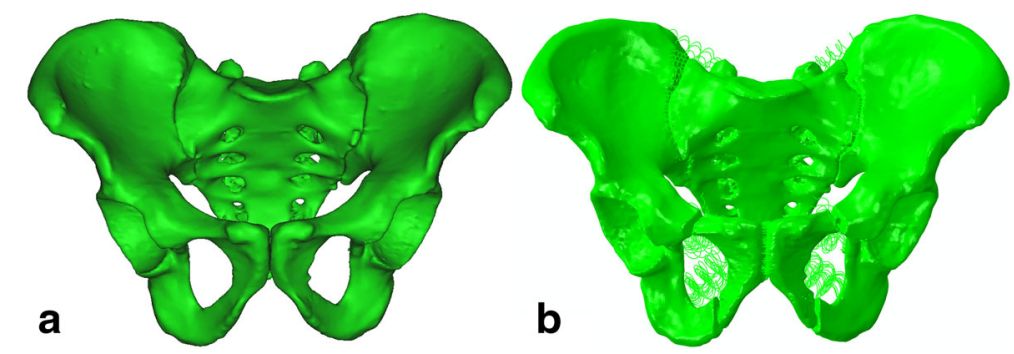

Fig. 1 The intact (a) and floating pubic symphysis (b) models

Depending on the energy level of the trauma, the mortality rate is between 18 and $25 \%$ in patients with hemodynamic instability [6]. Therefore, pathophysiological and hemodynamic stabilization should be considered carefully before surgical intervention is undertaken. For patients with hemodynamic instability, maneuvers should be performed to decrease pelvic volume and reduce motion of the bony fragments. The aim of these early damage control techniques is to achieve relative stability in a minimally invasive manner [7-10]. For patients who are hemodynamically stable, early definitive fixation can be undertaken with the goals being good functional recovery and a return to normal life. The purpose of definitive fixation is accurate reduction, rigid fixation, and minimal soft tissue disruption. There are several fixation methods used to treat FPS, including external fixation [11], anterior subcutaneous fixation $[10,12]$, internal fixation [13], and percutaneous cannulated screw fixation [14]. To choose the optimal fixation method, it is necessary to study the biomechanical performance of the different methods.

Therefore, the purpose of this study was to compare the biomechanical characteristics of six fixation methods for FPS using finite element analysis. Fixation methods were divided into three groups: external, subcutaneous, and internal fixation. In the subcutaneous group, there were two methods, subcutaneous rod and subcutaneous plate fixation. The superior pectineal plate (the ilioinguinal approach), infrapectineal plate (the modified Stoppa approach), and cannulated screw fixation were methods in the internal fixation group.

\section{Methods}

Finite element models and implants

The three-dimensional finite element model was obtained from the database of Shandong Provincial Hospital Affiliated to Shandong University. The reliability and validity was measured strictly by biomechanics laboratory. The model developed from $0.65-\mathrm{mm}$ thin-section computed tomography (Lightspeed VCT, GE, Fairfield, CT) scans of a healthy volunteer $(178 \mathrm{~cm}, 63 \mathrm{~kg}, 35$ years old, male). The values of window width, rows, and columns were 250,512 , and 512 , respectively. The DICOM format files of CT scans were processed using MIMICS 15.0 (Materialise, Belgium), and a bony pelvic model was created. The anterior sacroiliac, posterior sacroiliac, interosseous sacroiliac, sacrospinous, sacrotuberous, superior pubic, and arcuate pubic ligaments were added to the bony model in Abaqus 6.13 (3DS, Waltham, MA, USA) to simulate the normal skeleton-ligament system (Fig. 1a).

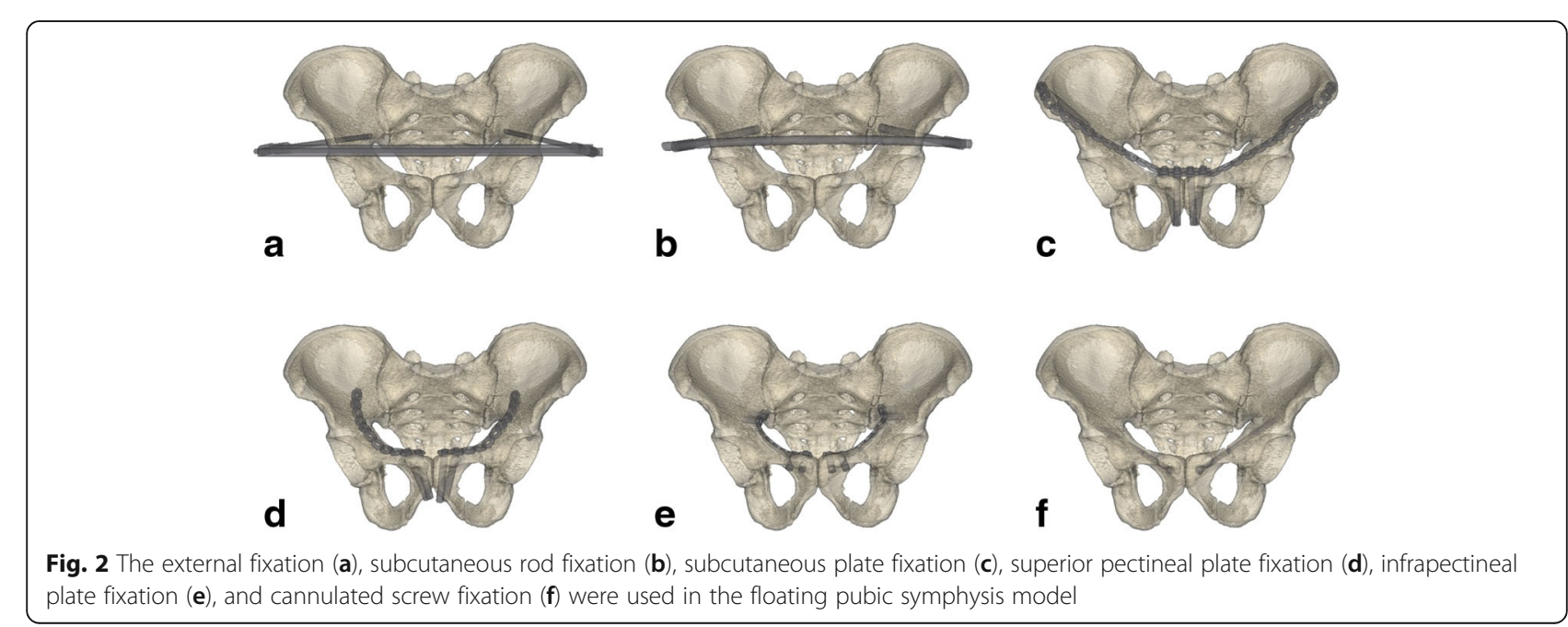


Table 1 Material properties of finite element models

\begin{tabular}{|c|c|c|c|c|}
\hline Material & $\begin{array}{l}\text { Elastic modulus } \\
(\mathrm{MPa})\end{array}$ & $\begin{array}{l}\text { Poisson's } \\
\text { ratio }\end{array}$ & $\begin{array}{l}K(\mathrm{~N} / \\
\mathrm{m})\end{array}$ & $\begin{array}{l}\text { Number } \\
\text { of springs }\end{array}$ \\
\hline \multicolumn{5}{|l|}{ Bone } \\
\hline Cortical bone & 18,000 & 0.3 & & \\
\hline Cancellous bone & 150 & 0.2 & & \\
\hline \multicolumn{5}{|l|}{ Ligaments } \\
\hline $\begin{array}{l}\text { Anterior and capsule } \\
\text { sacroiliac ligament }\end{array}$ & & & 700 & 27 \\
\hline $\begin{array}{l}\text { Posterior sacroiliac } \\
\text { ligament }\end{array}$ & & & 1400 & 15 \\
\hline $\begin{array}{l}\text { Interosseous sacroiliac } \\
\text { ligament }\end{array}$ & & & 2800 & 8 \\
\hline $\begin{array}{l}\text { Sacrospinous } \\
\text { ligament }\end{array}$ & & & 1400 & 9 \\
\hline $\begin{array}{l}\text { Sacrotuberous } \\
\text { ligament }\end{array}$ & & & 1500 & 15 \\
\hline $\begin{array}{l}\text { Superior pubic } \\
\text { ligament }\end{array}$ & & & 500 & 24 \\
\hline $\begin{array}{l}\text { Arcuate pubic } \\
\text { ligament }\end{array}$ & & & 500 & 24 \\
\hline Implants & 114,000 & 0.3 & & \\
\hline
\end{tabular}

The ligaments were simulated as non-linear spring elements. To simulate FPS (Fig. 1b), the model included 5-mm bone defects in the bilateral superior and inferior pubic rami.

Six fixation methods were used in the FPS model, including external fixation (Ext), subcutaneous rod fixation (Sub-rod), subcutaneous plate fixation (Sub-plate), superior pectineal plate fixation (Int-sup), infrapectineal plate fixation (Int-ifa), and cannulated screw fixation (Intscr) (Fig. 2). The external fixation apparatus (Constant, Wuhan, China) was mounted using two 5-mm apex self-drilling pins and two $8-\mathrm{mm}$ connecting rods. The diameters of the pedicle screws (Medtronic-WeiGao Inc., WeiHai, China) and connecting rod (Constant, Wuhan, China) in the Sub-rod fixation system were 8 and $8.5 \mathrm{~mm}$, respectively. The reconstruction plates (Synthes, Oberdorf, Switzerland) were 17-hole (x2) for the Sub-plate, 11-hole (x2) for the Int-sup, and 9-hole (x2) for the Int-ifa methods, respectively. The length and diameter of the cannulated screws (Synthes, Oberdorf, Switzerland) were 100 and $7.3 \mathrm{~mm}$, respectively. All implants were inserted into the FPS model using a standard surgical technique. The contact behavior of the screw-bone interface was set as a rigid bond and that of the plate-bone interface as surface-to-surface. The threads and screw heads of the cannulated screws were fully fixed into bones. The threads of the cortical screws were omitted to simplify the models.

The intact model without implants had a total of 769,120 elements and 204,680 nodes. The numbers of elements for implants were 86,682, 59,305, 198,675, $158,372,123,885$, and 59,168 for the Ext, Sub-rod, Subplate, Int-sup, Int-ifa, and Int-scr methods, respectively. The numbers of nodes for these implants were 20,696, $14,095,47,543,37,153,28,307$, and 16,332 , respectively.

\section{Finite element analysis}

The finite element analysis was performed using Abaqus 6.13. Linear elastic isotropic material properties were assigned to all models and implants. All contact elements were defined as deformable elements. The properties of the bones, ligaments, and implants [15] are shown in Table 1.

The superior segment of S1 in the models was fixed. The two types of load conditions that were used in all models were compression and rotation (Fig. 3). For compression, the vertical force of $250 \mathrm{~N}$ was distributed to each acetabulum. For rotation, a torque of $7 \mathrm{Nm}$ was applied to the pelvis to simulate rotation.

The biomechanical characteristics of the Ext, Sub-rod, Sub-plate, Int-sup, Int-ifa, and Int-scr models were analyzed and compared using the normal and FPS models. Construct stiffness was used to compare anterior pelvic ring stability. The stabilization of the fracture regions was
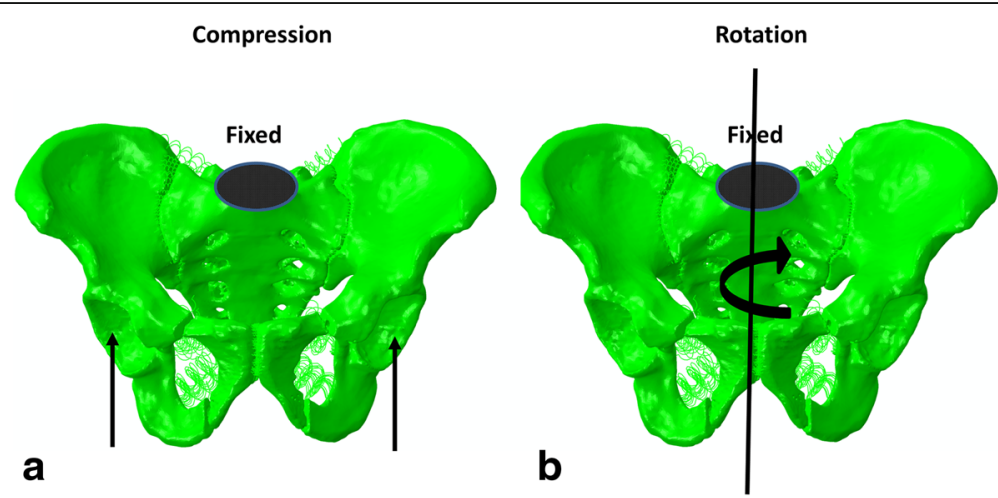

Fig. 3 The load conditions of finite element analysis. The superior segment of S1 of the models was fixed. Two types of load condition were used in all models, including compression (a) and rotation (b) 
Table 2 The construct stiffness of models

\begin{tabular}{lllllllll}
\hline Load condition & Nor & FPS & Ext & Sub-rod & Sub-plate & Int-sup & Int-ifa & Int-scr \\
\hline Compression (\%) & 100 & 61.49533 & 81.33454 & 97.50432 & 76.74699 & 105.5299 & 104.2795 & 90.46921 \\
Rotation (\%) & 100 & 42.34384 & 42.83913 & 43.98612 & 63.57524 & 69.24526 & 75.61063 & 70.69581
\end{tabular}

evaluated by recording the increments of micromotion of the fracture gaps. To evaluate the forces, stress distribution and maximum von Mises stress were measured.

\section{Results}

The construct stiffness of the different models under compression and rotation is displayed in Table 2. When FPS occurred, the construct stiffness of the anterior pelvic ring was decreased dramatically under both conditions. The compressive construct stiffness of FPS fixation using the Sub-rod, Int-sup, Int-ifa, and Int-scr methods were 61.495, $97.504,105.530,104.280$, and $90.469 \%$ of that seen in the normal model, respectively. In general, the compressive stiffness was restored by the internal fixation and Sub-rod methods. Unfortunately, rotational stiffness was not restored satisfactorily by the six methods. The method that best restored the rotational stiffness was the Int-ifa method, and the stiffness was only $75.6 \%$ of that seen in the normal model.

The incremental micromotion of the fracture region is shown in Table 3. The FPS model showed extreme instability. Under compressive loads, the displacement was reduced significantly by the internal fixation systems. The Int-sup and Int-ifa methods were the most effective, with displacement of only 0.068 and $0.045 \mathrm{~mm}$, respectively. Under rotational loads, the internal fixation systems and Sub-plate performed well with $0.048^{\circ}, 0.056^{\circ}, 0.005^{\circ}$, and $0.150^{\circ}$ of fracture region micromotion using the Int-sup, Int-ifa, Int-scr, and Sub-plate methods, respectively.

The von Mises stress of the implants is shown in Figs. 4 and 5 and Table 4. In general, the maximum von Mises stress of the implants was not large. The Sub-plate and Int-scr endured the highest level of stress. For the platescrew system, the maximum von Mises stress occurred over the region of the fracture and the plate-screw joints. With respect to the reconstruction plate, the molding sites, especially for the Sub-plate, endured the maximum von Mises stress. In the rod-screw system, the maximum von Mises stress appeared at the rod-screw and screwbone interfaces.

Table 3 The incremental micromotion of fracture region

\begin{tabular}{lccccccc}
\hline $\begin{array}{l}\text { Load } \\
\text { condition }\end{array}$ & FPS & Ext & Sub-rod & Sub-plate & Int-sup & Int-ifa & Int-scr \\
\hline $\begin{array}{l}\text { Compression } \\
(\mathrm{mm})\end{array}$ & 0.722 & 0.552 & 0.462 & 0.725 & 0.068 & 0.045 & 0.304 \\
Rotation $\left(^{\circ}\right)$ & 1.565 & 1.559 & 1.534 & 0.150 & 0.048 & 0.056 & 0.005 \\
\hline
\end{tabular}

In summary, the level of stability of the anterior pelvic ring and fracture regions was highest using the internal fixation methods, followed by the subcutaneous fixation methods, and lowest using external fixation. Interestingly, the Sub-rod and Sub-plate showed completely different characteristics. The Sub-rod offered satisfactory anti-compression, while the Sub-plate provided better anti-rotational capacity.

\section{Discussion}

FPS is a life-threatening injury characterized by an unstable anterior pelvic ring and hemodynamic instability. The instability of the pelvic ring is caused by fractures of the bilateral superior and inferior pubic rami and ischial rami. The mortality rate is $8.5-19 \%$ in polytrauma patients with pelvic fractures [6]. Shockingly, the mortality rate increases to $18-25 \%$ in patients with hemodynamic instability [6]. Moreover, the risk of internal organ injuries increases when there are migrating fracture fragments [5]. Thus, patients with FPS require emergency pelvic stabilization to help minimize the mortality rate. Several fixation methods have been applied under such circumstances, including external fixation, anterior subcutaneous fixation, internal plate fixation, and percutaneous cannulated screw fixation. To choose the optimal fixation method, it is necessary to study the biomechanical performance of the different methods. Therefore, the aim of this study was to compare the biomechanical characteristics of six methods using finite element analysis.

External fixation remains the gold standard in the emergent treatment of anterior pelvic fractures [6], especially in patients with hemorrhagic shock and/or significant soft tissue damage. However, there are disadvantages to using an external fixator, including pin tract infection, loosening, skin impingement by pins, osteomyelitis, inconvenience regarding wound care and mobility, and negative effects on a patient's quality of life $[16,17]$. Particularly in diabetic and obese patients, external fixation is not recommended $[16,18]$. External fixation can be a definitive treatment when accurate reduction and adequate fixation is obtained. Unfortunately, our results showed that external fixation did not meet these criteria from a biomechanical point of view. Under both compressive and rotational loads, the construct stiffness of the anterior pelvic ring was the lowest with external fixation. Failure to achieve and maintain stability of the fracture fragments can lead to recurrent bleeding and secondary internal organ injuries. Post-operative fragment dislocation is also a result of 


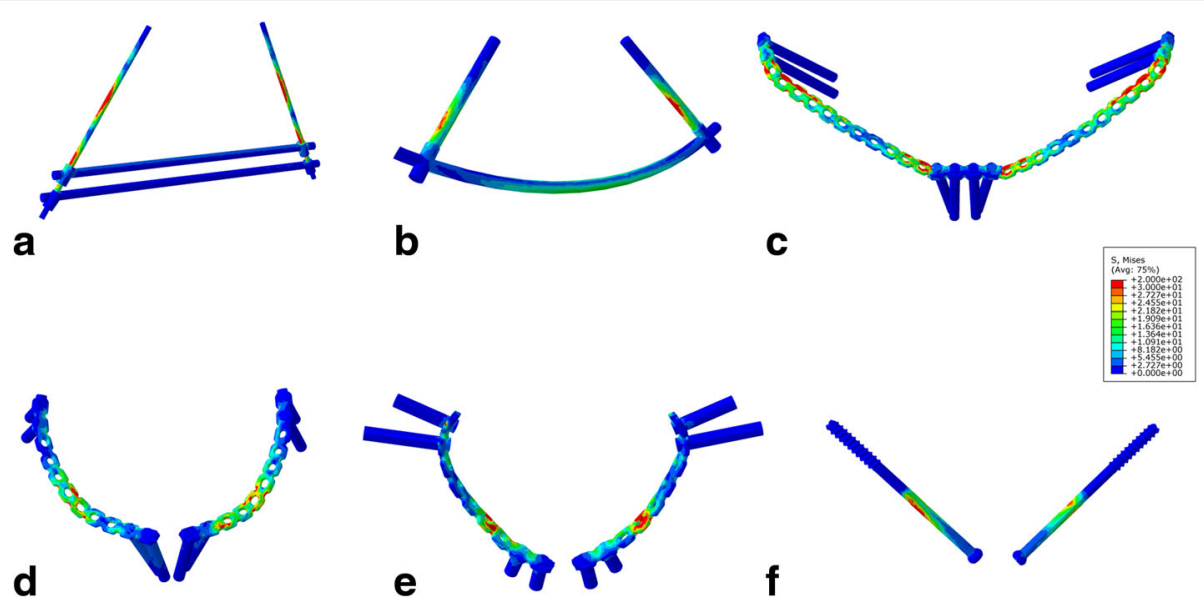

Fig. 4 The von Misses stress of external fixation (a), subcutaneous rod fixation (b), subcutaneous plate fixation (c), superior pectineal plate fixation (d), infrapectineal plate fixation (e), and cannulated screw fixation (f) under compressional load condition

deficient fixation, and there are multiple secondary injuries that can be caused by unstable fracture fragments. Therefore, methods achieving increased construct stiffness may be necessary for definitive treatment after emergent stabilization has been performed.

We applied two techniques for achieving subcutaneous anterior fixation, including the use of a rod [18] and a plate [12]. These techniques have been performed in several cases. According to those who developed these methods $[10,17]$, subcutaneous fixation is appropriate in patients with hemodynamic instability. Operative time is comparable to that seen with external fixation, and the complication rate was reported to be lower. However, different complications including irritation of the lateral femoral $\mathrm{cu}-$ taneous nerve and heterotopic ossification formation were shown to occur with subcutaneous rod fixation. The plate is not easy to apply in the setting of FPS due to difficulty in achieving reduction. From a biomechanical perspective, our results showed that subcutaneous anterior fixation achieves greater stiffness than external fixation. Interestingly, the subcutaneous rod fixator responded well to compression, while the subcutaneous plate fixator provided favorable anti-rotational capacity. This may be because the rod is ilium-ilium fixation and the plate is ilium-pubis-ilium fixation.

With regard to internal plate fixation methods, our study showed no significant difference between the use of the superior pectineal plate and infrapectineal plate. Both provided adequate stability from a biomechanical perspective. Indications for fixation methods depend on the fracture pattern and should be an area of future clinical research. Cannulated screws are an alternative option that have had good outcomes with use in FPS. This technique avoids extensive surgical exposure and minimizes the complications often experienced with reconstruction plates [14]. Furthermore, cannulated screws can achieve similar biomechanical results to internal fixation. Percutaneous cannulated screw fixation can provide accurate closed reduction and

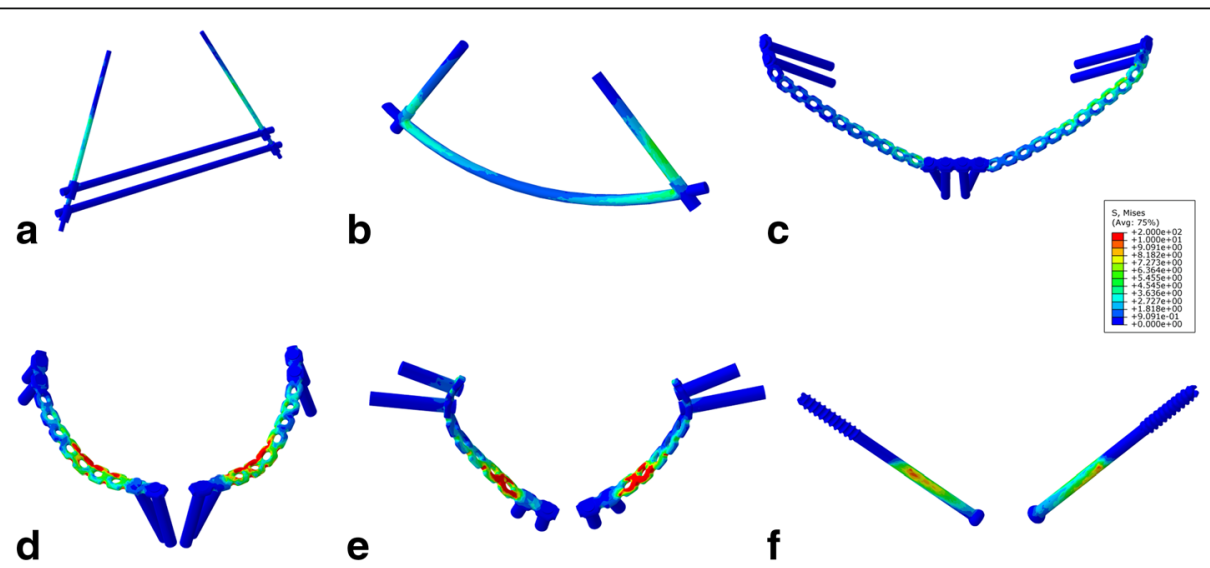

Fig. 5 The von Misses stress of external fixation (a), subcutaneous rod fixation (b), subcutaneous plate fixation (c), superior pectineal plate fixation (d), infrapectineal plate fixation (e), and cannulated screw fixation (f) under rotational load condition 
Table 4 The maximum von Misses stress of implants

\begin{tabular}{lllllll}
\hline $\begin{array}{l}\text { Load } \\
\text { condition }\end{array}$ & Ext & Sub-rod & Sub-plate & Int-sup & Int-ifa & Int-scr \\
\hline $\begin{array}{l}\text { Compression } \\
\begin{array}{l}\text { (MPa) } \\
\text { Rotation }\end{array}\end{array}$ & 133.148 & 108.481 & 214.616 & 165.828 & 126.683 & 218.38 \\
\begin{tabular}{l} 
(MPa) \\
\hline
\end{tabular} & 12.536 & 9.452 & 25.739 & 61.783 & 62.87 & 30.343 \\
\hline
\end{tabular}

rigid fixation and is an excellent option for the treatment of patients with hemodynamic instability and soft tissue damage [14]. This technique can be performed in both emergent and delayed stabilization. Reduced operative times and diminished blood loss are advantages of percutaneous cannulated screw fixation which help to contribute to lower complication rates. However, frequent intra-operative fluoroscopy using a navigation system is required for accurate screw insertion.

Additionally, it should be mentioned that FPS is often associated with posterior pelvic ring injuries that cannot be restored and stabilized using the fixation methods previously described. Posterior pelvic ring stabilization can be achieved by percutaneous sacroiliac screws or other methods. In the present study, we maintained an intact posterior pelvic ring to minimize confounding factors. This was a limitation of our research.

There were other limitations of this study. The finite element models were based on a skeleton-ligament system, and thus, the muscle forces were not accounted for. This is similar to other finite element studies. A single pelvic model was used for analysis, which may neglect the bony and ligamentous variation seen between people. In the current study, we used the Chinese external fixation system, Constant. Considering that different implants have disparate designs, the results of this research can only be generalized to similar external fixators. The present study was designed to evaluate the biomechanical characteristics of six methods in the treatment of FPS, but pathophysiological and hemodynamic stabilization was not considered. Additional aspects of surgical treatment should be addressed in future clinical studies.

\section{Conclusions}

In conclusion, from the finite element view, the present study showed the biomechanical advantages of internal fixation for FPS compared with external fixation. Improved stabilization of the anterior pelvic ring and fracture gaps was obtained using internal fixation. Subcutaneous fixation had satisfactory outcomes as well. The Sub-rod fixation offered good anti-compression, while Sub-plate fixation provided favorable anti-rotational capacity.

\section{Abbreviations}

CT: Computed tomography; Ext: External fixation; FPS: Floating pubic symphysis; Int-ifa: Infrapectineal plate fixation; Int-scr: Cannulated screw fixation; Int-sup: Superior pectineal plate fixation; Sub-plate: Subcutaneous plate fixation; Sub-rod: Subcutaneous rod fixation

\section{Acknowledgements}

Not applicable.

\section{Funding}

No funding was received.

Availability of data and materials

Please contact author for data requests.

\section{Authors' contributions}

DZ, YH, and WS drafted the manuscript. WS and YH contributed to the acquisition of the data, the analysis, and the interpretation of the data. DZ and $\mathrm{YH}$ participated in the conception, design, and coordination. DZ and YH supervised the whole study. All authors read and approved the final manuscript.

\section{Competing interests}

The authors declare that they have no competing interests.

Consent for publication

Not applicable.

\section{Ethics approval and consent to participate}

This study was done at the Shandong Provincial Hospital Affiliated to Shandong University, and permission was obtained from the hospital Ethics Committee. Authors had to obtain patient consent before enrolling participants in this study.

Received: 28 June 2016 Accepted: 23 February 2017

Published online: 07 March 2017

References

1. Owens B, Goss TP. The floating shoulder. J Bone Joint Surg Br. 2006;88(11): 1419-24.

2. Liebergall $M$, Mosheiff $R$, Safran $O$, Peyser $A$, Segal $D$. The floating hip injury: patterns of injury. Injury. 2002;33(8):717-22.

3. Dwyer A, Paul R, Mam M, Kumar A, Gosselin R. Floating knee injuries: longterm results of four treatment methods. Int Orthop. 2005;29(5):314-8.

4. Agarwal A, Chadha M. Floating injuries: a review of the literature and proposal for a universal classification. Acta Orthop Belg. 2004;70(6):509-14.

5. Dong J-I, D-s Z. Management and outcome of open pelvic fractures: a retrospective study of 41 cases. Injury. 2011:42(10):1003-7.

6. Poenaru DV, Popescu M, Anglitoiu B, Popa I, Andrei D, Birsasteanu F. Emergency pelvic stabilization in patients with pelvic posttraumatic instability. Int Orthop. 2015;39(5):961-5.

7. Gardner MJ, Mehta S, Mirza A, Ricci WM. Anterior pelvic reduction and fixation using a subcutaneous internal fixator. J Orthop Trauma. 2012; 26(5):314-21.

8. Hiesterman TG, Hill BW, Cole PA. Surgical technique: a percutaneous method of subcutaneous fixation for the anterior pelvic ring: the pelvic bridge. Clin Orthop Relat Res. 2012:470(8):2116-23.

9. Enninghorst N, Toth L, King KL, McDougall D, Mackenzie S, Balogh ZJ. Acute definitive internal fixation of pelvic ring fractures in polytrauma patients: a feasible option. J Trauma Acute Care Surg. 2010;68(4):935-41.

10. Müller FJ, Stosiek W, Zellner M, Neugebauer R, Füchtmeier B. The anterior subcutaneous internal fixator (ASIF) for unstable pelvic ring fractures. Clinical and radiological mid-term results. Int Orthop. 2013;37(11):2239-45.

11. Stahel PF, Mauffrey C, Smith WR, McKean J, Hao J, Burlew CC, Moore EE. External fixation for acute pelvic ring injuries: decision making and technical options. J Trauma Acute Care Surg. 2013;75(5):882-7.

12. Cole PA, Gauger EM, Anavian J, Ly TV, Morgan RA, Heddings AA. Anterior pelvic external fixator versus subcutaneous internal fixator in the treatment of anterior ring pelvic fractures. J Orthop Trauma. 2012;26(5):269-77.

13. Ponsen K-J, Joosse P, Schigt A, Goslings CJ, Luitse JS. Internal fracture fixation using the Stoppa approach in pelvic ring and acetabular fractures: 
technical aspects and operative results. J Trauma Acute Care Surg. 2006; 61(3):662-7.

14. Winkelhagen J, van den Bekerom MP, Bolhuis HW, Hogervorst M. Preliminary results of cannulated screw fixation for isolated pubic ramus fractures. Strategies Trauma Limb Reconstr. 2012;7(2):87-91.

15. Yao F, He Y, Qian H, Zhou D, Li Q. Comparison of biomechanical characteristics and pelvic ring stability using different fixation methods to treat pubic symphysis diastasis: a finite element study. Medicine. 2015 94(49), e2207.

16. Eagan M, Kim H, Manson TT, Gary JL, Russell JP, Hsieh AH, OToole RV, Boulton CL. Internal anterior fixators for pelvic ring injuries: do monaxial pedicle screws provide more stiffness than polyaxial pedicle screws? Injury 2015:46(6):996-1000.

17. Osterhoff G, Tiziani S, Ferguson SJ, Spreiter G, Scheyerer MJ, Spinas G-L, Wanner GA, Simmen H-P, Werner CM. Mechanical testing of a device for subcutaneous internal anterior pelvic ring fixation versus external pelvic ring fixation. BMC Musculoskelet Disord. 2014;15(1):111.

18. Sellei RM, Dienstknecht T, Brücken D, Pfeifer R, Pape H-C. Percutaneous anterior internal pelvic fixator. Oper Tech Orthop. 2013;23(1):33-7.

Submit your next manuscript to BioMed Central and we will help you at every step:

- We accept pre-submission inquiries

- Our selector tool helps you to find the most relevant journal

- We provide round the clock customer support

- Convenient online submission

- Thorough peer review

- Inclusion in PubMed and all major indexing services

- Maximum visibility for your research

Submit your manuscript at www.biomedcentral.com/submit
Biomed Central 